\title{
Association of cyberbullying with psychosocial difficulties, self-harm and helping-seeking behaviors: a cross section study in Singapore adolescents
}

Say How Ong ( $\nabla$ say_how_ong@imh.com.sg )

Institute of Mental Health https://orcid.org/0000-0002-7735-4566

Yi Ren Tan

Institute of Mental Health

Jerrine Z. N. Khong

Singapore Children's Society

John M. Elliott

National University of Singapore

Andre Sourander

Turun Yliopisto

Daniel S. S. Fung

Institute of Mental Health

Research article

Keywords: Cyberbullying, internalising problems, externalising problems, self-harm, suicidal behaviors

Posted Date: January 9th, 2020

DOI: https://doi.org/10.21203/rs.2.20388/v1

License: (c) (i) This work is licensed under a Creative Commons Attribution 4.0 International License.

Read Full License 


\section{Abstract}

Background Social media use has constituted to significant time spent online by adolescents globally, with its untoward effects increasingly being reported in many countries. Bullying through the use of such media has afflicted many adolescents to cause severe mental health concerns including self-harm and suicide.Aims The aims of this study are to examine the prevalence of cyberbullying in Singapore adolescents, its associations with psychosocial issues including self-harm and suicidal behaviors, and how adolescents seek help after being cybervictimised.

Methods A representative sample of 3,319 school students aged between 12 and 17 years were recruited in this cross-sectional study and responded to a survey with scales measuring cyberbullying, psychosocial difficulties, self-harm, suicidal and help-seeking behaviors. The prevalence rate of cyberbullying was first explored using descriptive statistics, followed by Pearson chi-square tests for independence, one-way ANOVA tests and multinomial logistics regressions to examine its associations with various psychosocial issues.

Results In the present study, $7.3 \%$ of adolescents reported being cybervictims only, $1.8 \%$ were cyberbullies only and $4.8 \%$ were cyberbully-victims. Compared to the non-involved group, all three cyberbullyinginvolved groups were associated with higher externalising problems $[F(3,3290)=62.06, p<.001]$, but only both cybervictim and cyberbully-victim groups were associated with more internalising problems [ $\mathrm{F}$ $(3,3290)=38.97, p<.001]$. Similarly, both cybervictim and cyberbully-victim groups reported significantly higher incidence of self-harm behaviors, suicidal thoughts and attempts as compared to the non-involved group (Odds ratios $=2 \cdot 6-5.0$, all p s $<.001$ ). Cyberbullies, on the other hand, had increased odds in having suicidal attempts (Odds ratio $=3.9, p<.001$ ). Approximately half of the cybervictimised participants reported that they have sought help, with most of them (81.7\%) choosing to tell their friends.

Conclusions Our findings are consistent with previous studies showing increased associations of psychosocial difficulties, self-harm and suicidal behaviors among adolescents who are involved in cyberbullying. Public awareness of the consequences of unhealthy cyber-usage could be raised to aid in early detection of cyberbullying among school children and adolescents. Moreover, cyberwellness programmes should be considered as a component of larger suicide prevention efforts in schools and in the community.

\section{Background}

The cyberspace has brought about greater connectivity to people globally since its existence in the eighties. Singapore, a young nation of 5.5 million occupants, ranks among the top 4th Asian country in terms of internet penetration rate and the 9th country internationally in terms of mobile social media penetration ranking [1]. Accompanying this high prevalence of digital media use is a unique set of problems involving issues with cyber-security and individuals' right to privacy, to name a few. Cyberbullying has also become more prevalent particularly in children and adolescent populations. 
Often seen as an extension of traditional bullying [2-4], the prevalence rate of cyberbullying varies across countries and continents, with a lifetime prevalence worldwide between $2 \%$ and $35 \%$ [5-7]. In Asia, for example South Korea, approximately one out of three 7th to 12th grade students surveyed was involved in cyberbullying [8] while another study by Jung and colleagues [9] cited a rate of $9.7 \%$, which is closer to the $10.1 \%$ reported by the EU Kids Online Study [10]. The phenomenon of cyberbullying in Singapore children has been examined in a few local studies. For example, Ang and Goh [11] studied 396 adolescents of ages between 12 to 18 years and found that $3.7 \%$ of boys and $0.9 \%$ of girls engaged in cyberbullying on a frequent basis. In another local study on Facebook bullying by Kwan and Skoric [12], out of 1597 participants aged 13-17 years old surveyed from two secondary schools, $59.4 \%$ of them reported being cyberbullied on Facebook. This vast difference in rates could be due to the varied definitions of cyberbullying and how it is being operationalised in research $[13,14]$. This disparity therefore highlights the need for more research using a representative sample in Singapore.

Studies on traditional face-to-face bullying have long documented a variety of psychosocial problems in those involved in bullying. While there are some studies which showed equal or more internalising problems in traditional bullying [15-17] compared to cyberbullying, other studies $[18,19]$ found that cybervictims reported more psychosocial difficulties than traditional victims. Perren and colleagues [20] discovered that even after controlling for involvement in traditional bullying or victimisation, cybervictims reported significantly higher rate of depressive symptoms. Concurrently, significant research in western countries has shown an association between cybervictimisation and emotional problems including suicidal behaviours [2, 21-24]. However, there have been limited studies in Singapore exploring psychosocial consequences of cyberbullying. Therefore, we want to examine such associations in the local setting.

In recent years, cyberbullying has unfortunately claimed substantial media spotlight with reports of youth suicides and increased hospitalisation rates for suicidal behaviours in the United States following cyberbullying [25]. Suicide to date is the second leading cause of death among 15- to 19-year-olds worldwide [26] with approximately $5-8 \%$ of adolescents having made suicide attempts in the US [27]. Suicidal behaviours typically include suicidal ideation, suicide plan and suicide attempt, which are distinguished by most researchers and clinicians from non-suicidal self-injury [28]. As suggested by the interpersonal theory of suicide [29], poor sense of belongingness and perceived burdensomeness are some of the potential causes of suicidal desire and attempts, which are associated with experience of cybervictimisation [30]. Hinduja and Patchin [2], in their seminal study examining the association of cyberbullying with suicide ideations in 1,963 middle-schoolers, reported suicide attempt rates at 1.9 times and 1.5 times more for cybervictims and cyberbullies respectively when compared to those who were no involved in cyberbullying in any way. This may be due to an increased risk of being depressed and anxious among cybervictims as illustrated by a Korean study on 490 middle school students [31]. Similar to cybervictims, cyberbully-victims (who are both perpetrators and victims) are also at higher risk for emotional problems such as anxiety and depression in addition to peer problems (e.g. generally liked by other children, has at least one good friend) and lower self-esteem $[6,10]$. With that, they may suffer for even higher risk of suicidal behaviours. Interestingly, given the comparable economy, education and 
general quality of healthcare between Singapore and other Asian countries like Japan and South Korea, the crude suicide rate of adolescents aged 10-19 years in Singapore is significantly lower at 3.7 per 100,000 compared to rates of these two countries (Japan at 4.8 per 100,000 and South Korea at 4.4 per $100,000)$ [32]. This observation may suggest a difference in pathway leading to suicidality of adolescents involved in cyberbullying across different Asian countries.

\section{Objectives}

Given the diverse findings by researchers worldwide and the limited research conducted in Singapore despite having one of the world's highest internet penetration rate and social media users, this study aims to examine the prevalence of cyberbullying in Singapore adolescents, its associations with psychosocial issues and how do the adolescents seek help after being involved in cyberbullying. The study hypothesises that both cyberperpetration and cybervictimisation are associated with greater internalising and externalising problems. The second hypothesis is that cyberbullying is associated with higher rate of suicidal behaviors including self-harm, suicidal thinking and suicidal attempts.

\section{Methods}

\section{Procedure}

This self-report, cross-sectional study was carried out in 2014 in Singapore. The study design and questionnaires were adapted from Sourander and colleagues [33] as part of an international study investigating the impact of cyber environments on adolescents. In the current study, approval was obtained from the local research ethics committee. Permission was also obtained from the Ministry of Education prior to conducting the research.

A two-stage sampling strategy was employed. First, schools were randomly sampled from a list of local mainstream schools, which were stratified according to their types (i.e., degree of autonomy in school operations and amount of government funding) and geographical areas (i.e., north, south, east and west). Invitation letters were sent to the selected schools' principals to explain the study rationale and design. Should any school declined to participate, the next school within the same strata was approached following the original stratification plan. A total of 28 schools ( 24 secondary schools, three junior colleges and one polytechnic) agreed to take part in the study. In the second stage, planned recruitment of approximately 120 students (four classes) from each participating school was conducted in order to achieve representative educational levels and academic streams (i.e., based on students' performance in a national examination prior to secondary school entry) across the sample.

A passive consent procedure was used in this study and was approved by the ethics committee. All parents from the participating classes were informed about the study through written communication prepared by the investigaters and handed out by the schools at least two weeks prior to the scheduled questionnaire administration. Parents were requested to contact the school if they did not want their child 
to participate in the study. Assent was also obtained from the participants before they completed the online survey in their respective computer laboratories or classrooms. They were reminded about the anonymity and voluntary nature of the study participation. The overall participation rate was $85.8 \%$. Data collection was conducted in school by study team members, which took approximately 30 to 45 minutes during school days.

\section{Participants}

A total of 3,329 students participated in the study. Ten participants were excluded from analyses as they provided invalid responses. The final sample consisted of 3,319 students with equal gender distribution (1665 males, 50.2\%) and roughly proportionate educational levels. Their age ranged from 12 to 17 years $(M=14.42, S D=1.48)$. Self-reported ethnic identification was as follows: $66.4 \%$ of the participants were Chinese, $22.1 \%$ were Malay, $6.0 \%$ were Indian and 5.5\% endorsed Others (all other ethnic groups not listed). The distribution of ethnicity was proportionate to that of the Singapore population aged 10-19 years (34).

\section{Data sources and collection tools}

\section{Cyberbullying}

In order to improve the validity of responses, participants were provided with the definition of cyberbullying adapted from Hinduja and Patchin [35] who described cyberbullying as a phenomenon "when someone repeatedly makes fun of another person online or repeatedly picks on another person through email or text messages or when someone posts something online about another person that they don't like".

Participants were asked how often they have been cyberbullied and/or cyberbullied others in the past six months. These two items were rated on a 4-point Likert scale ranging from: 1 - 'Never', 2 - 'Less than once a week', 3 - 'More than once a week' and 4 - 'Almost every day'. Similar to Sourander and colleagues [33], responses ' 2 ' or more were referred to cyberbullying or being cybervictimised at least sometimes and hence were used for the subsequent categorisation. Based on their responses, participants were categorised into four groups: (1) Non-involved; (2) Cybervictim only; (3) Cyberbully only; and (4) Both cyberbully and cybervictim (cyberbully-victim).

\section{Emotional and behavioral difficulties}

The youth self-report version of the Strengths and Difficulties Questionnaire (SDQ) [36] was used to assess emotional and behavioral difficulties. It consists of 25 items divided into five subscales, which include emotional problems, peer problems, conduct problems, hyperactivity-inattention and prosocial behavioral subscales. Each scale comprises five items on a 3-point Likert scale ranging from: 0 - 'Not true', 1 - 'Somewhat true' and 2 - 'Certainly true'. To handle missing data, summation of each subscale was conducted if there are at least three valid items. 
As participants in the current study were from the general population, broader internalising and externalising subscales were used in this study [37]. Internalising problem subscale was computed by summating emotional and peer problem subscales (Cronbach's alpha $=.70$ ), while externalising problem subscale was a summation of conduct problem and hyperactivity/inattention subscales (Cronbach's alpha $=.65)$. Higher scores on these two subscales indicated more difficulties reported by the adolescents.

\section{Self-harming and suicidal behavior}

Three questions relating to self-harming and suicidal behaviours with yes/no responses were utilised in the study [33]. Participants responded whether they have ever hurt themselves deliberately (e.g., cutting), thought seriously about committing suicide and tried to commit suicide.

\section{Help-seeking behaviour}

Participants were asked if they have told someone about their bullying experience in order to receive help [33], and if so, who have they told: parent, siblings, friend, teacher, other adult at school (e.g., principal, counsellor) and mental health professional (e.g., psychiatrist, psychologist, social worker). They were allowed to indicate multiple individuals as their responses.

\section{Data synthesis}

\section{Statistical Analysis}

Analyses were performed using IBM SPSS Statistics, Version 20. Frequencies of cyberbullying status (i.e., non-involved, cybervictim, cyberbully and cyberbully-victim) were first explored to determine the prevalence rates of cyberbullying in Singapore. Pearson chi-square tests for independence and one-way ANOVA were conducted to investigate if there are any gender, ethnicity and age differences across cyberbullying groups. To further examine help-seeking behaviours, only cybervictimised participants (i.e., cybervictim and cyberbully-victim) were included. Patterns of help-seeking behaviours were explored with chi-square tests for independence to examine gender differences, if any.

Mean differences of the two SDQ subscales across cyberbullying groups were examined using one-way ANOVA tests with Bonferroni tests as post-hoc pairwise comparison. Furthermore, multinomial logistics regressions were conducted individually for self-harming and suicide-related behaviours to examine their associations among cyberbullying groups. Odds ratios (ORs) and $95 \%$ confidence intervals (Cls) were presented. Non-involved group was used as reference and all analyses were adjusted for gender, age and ethnicity. Given the large sample size and multiple comparisons, a more conservative $p$ value $(p<.001)$ was used in this study.

\section{Results}




\section{Cyberbullying Status}

In the present study, out of a final sample of 3,319 students, majority of the participants $(86.1 \% ; n=2845)$ were not involved in any form of cyberbullying; $7.3 \%(n=240)$ of them reported being cybervictims only, $1.8 \%(n=60)$ were cyberbullies only and $4.8 \%(n=160)$ were cyberbully-victims.

Table 1 presents demographic characteristics of the cyberbullying status groups. Chi-square tests for independence revealed significant gender differences across the groups. Further examination of adjusted residuals (i.e., Adj. Res. > 2.0) indicated that female students were more likely to report as being cybervictims. On the other hand, male students were more likely to be involved as cyberbullies and cyberbully-victims. No significant ethnicity and age differences were observed across the groups.

$===$ Insert Table 1 about here $===$

\section{Emotional and Behavioural Difficulties}

There were significant differences among cyberbullying status groups on SDQ internalising problem subscale scores, $F(3,3290)=62.06, p<.001, \eta^{2}=.054$. Post-hoc pairwise comparisons using Bonferroni corrections (see Table 2) indicated that those who were not involved in cyberbullying reported lesser internalising problems than cybervictims and cyberbully-victims. No significant differences were found among other pairwise comparisons.

In terms of externalising problems, results showed significant differences among cyberbullying status groups, $F(3,3290)=38.07, p<.001, \eta^{2}=.034$. As indicated in Table 2, post-hoc comparisons revealed that those who were not involved in cyberbullying scored significantly lower externalising problems as compared to all three other groups.

$===$ Insert Table 2 about here $===$

\section{Self-harming and Suicidal-related Behaviors}

Table 3 presents results of multinomial logistic regressions after controlling for the effect of gender, ethnicity and age. Compared to non-involved group, those who were cybervictimised (i.e., cybervictims and cyberbully-victims) had increased odds of having self-harm behaviours, suicidal ideations and suicidal attempts. There were also increased odds of suicidal attempts among cyberbullies as compared to non-involved group.

$===$ Insert Table 3 about here $===$

\section{Help-seeking Behavior}

Approximately half of the cybervictimised participants $(52.1 \%, \mathrm{n}=208)$ reported that they have told someone about their experience in order to receive help. Chi-square tests for independence with continuity correction found no significant difference in help-seeking behaviours between cybervictim and cyberbullyvictims, $\chi 2(1, n=399)=2.29, p=.13$, Cramer's $V=.08$. As shown in Table 4, female participants were 
found to be more likely to seek help. Among those who sought help, most of them chose to tell their friends $(81.7 \%)$, followed by parents $(40.9 \%)$, siblings (31.7\%) and teachers $(25.5 \%)$. Relatively fewer participants told other adults at school (e.g., principal, counsellor; $15.4 \%$ ) and mental health professionals (e.g., psychiatrist, psychologist; 7.7\%). Chi-square tests for independence with continuity correction found no significant gender differences across all help-seeking sources.

$===$ Insert Table 4 about here $===$

\section{Discussion}

The present study aims to examine the prevalence of cyberbullying in Singapore and its associations with various psychosocial correlates. We found that $13.9 \%$ of adolescents were involved in cyberbullying, either as victims and/or bullies. This figure is much lower than another local study of Facebook users [12], which captured incidence of cyberbullying over a one-year period instead of six months and recruiting subjects from only two government secondary schools. Also, we used a narrower measure for cyberbullying which was adapted from Sourander and colleagues [33]. Female adolescents were more likely to be cybervictimised while males had higher cyberbullying perpetration rates. On the other hand, no ethnicity and age difference among groups were detected, which are consistent with previous studies [21].

Consistent with our first hypothesis, all three groups (cyberbully, cyberbully-victim and cybervictim) were associated with higher externalising problems, but only both cybervictim and cyberbully-victim groups were associated with more internalising problems. All three cyberbullying-involved groups reported significantly higher incidence of self-harm behaviours, suicidal thoughts and attempts as compared to the non-involved group, though to a lesser degree among cyberbullies thus supporting our second hypothesis that involvement in cyberbullying is associated with higher rates of suicidal behaviours and self-harm. Some studies $[23,38,39]$ have further reported that cyberbullying victimisation serve as predictors of depressive symptoms and suicidal ideation, which explain the associations found in this study. However, while cyberbullies were also more likely to report self-harm and suicidal behaviours, the lack of association between cyberperpetration and internalising problems in our study may suggest a different path for the cyberbullies for local adolescents. This observation perhaps may explain the difference in suicide rates between Singapore adolescents aged 10-19 years and those from other comparable Asian countries with high Internet penetration rate such as Japan and South Korea. Further studies can be conducted to explore such mechanisms.

Our findings also suggested that cyberbully-victims experienced both the emotional problems associated with victimisation as well as the behavioral difficulties associated with bullies, which is consistent with the literature [40,41]. There is also existing evidence that this group suffers from greater psychological impact as compared to pure cybervictim group [23, 39, 42, 43]. Others hypothesised that bullies who were victims previously had elevated suicidal risks due to their underlying psychopathology and 
accompanying psychosomatic problems [44]. More longitudinal studies set across different cultures and ethnicities would be well positioned to replicate these findings.

Close to fifty-two percent of cybervictims spoke to at least a friend about their predicament but did not disclose the bullying incidents to parents or school personnel. This finding corresponds to results from other studies [19] but raises a concern that victims may not be receiving the help they need from adults. The preference for majority (81.7\%) opting to disclose information to friends perhaps reflects the ageappropriate psychosocial development during which peer bonding and support are most highly regarded by adolescents at this stage. The reasons of non-disclosure to responsible adults could include being afraid that their phones/computers will be taken away, or that the bullying would come back even stronger after telling teachers about it. There could also be underlying mistrust of school personnel in that they are unlikely to intervene even if bullying incidents were reported to the school authorities. This mistrust could be attributable to perceived lack of connectedness to adults [45]. The experience of anger, embarrassment, worry and fear [18, 46-48] from being cyberbullied could possibly generate concurrent negative school experiences, poor school attachment [49], and negative perceptions of school climate [50]. Possible concerns of cybervictims and bystanders on reporting cyberbullying incidents in the local setting could be further studied to aid our understanding of the obstacles toward reporting.

\section{Strength And Limitations}

This work is strengthened by the inclusion of schools that are representative of varied student academic profiles locally. However, the measures of cyberbullying, self-harm and suicidal behaviors used relied mostly on single item questions and most questionnaires had not been validated locally. This was because we have adapted our study to be consistent with a comparable study by Sourander and colleagues [33] and to date, the debate on what constitutes as valid tools to measure cyberbullying remains. In addition, causal relationship and directionality cannot be established due to the crosssectional nature and sampling method of the study. While significant associations were found between cyberbullying involvement and psychosocial correlates, we are not able to determine if these emotional and behavioral difficulties are the cause or effect of cyberbullying involvement. Future longitudinal studies are needed to establish the causal relationships. Our current study also only examined cyberbullying and did not look at the effect of traditional bullying, which has been described elsewhere [51]. As our data were based on adolescents' self-reports, findings in the study may be affected by shared method variance and social desirability. Future research could consider the use of multiple informants' reports. It would also be interesting to explore the differences in help-seeking behaviors between cyberbully-victims and cyber victims.

\section{Implications for policy, practice and research}

Our study revealed a significant rate of cyberbullying taking place in adolescents aged 12 to 17 years old. A consistent finding is that cybervictims typically do not tell adults about their experiences or seek help from them. With cybervictims spending substantial amount of time in school, teachers and school 
personnel are well positioned to educate, intervene and mitigate the negative effects of cyberbullying. The Singapore Ministry of Education (MOE) has adopted the framework of Social and Emotional Learning (SEL) to help students acquire the necessary skills, knowledge and dispositions to manage self and relationships effectively and make responsible decisions essential for personal and social well-being [52]. Research has shown a strong link between SEL and student outcomes in the areas of mental well-being, character development, school success amongst others, and of which is built on the foundation of safe and caring school environment and positive teacher-student relationship [53].

Restorative practice, typically used in the criminal justice system, has also been applied to cases involving cyberbullying to bring about restitution, validation of feelings and assurance that bullying will not occur again [54]. Conferences are organised for both victims and bullies including their adult family members, and facilitated by trained practitioners such as teachers, coaches or school administrators. Based on a central value of accountability [55], restorative practice allows victims to feel empowered and reassured that the bullying stops, and help offenders build empathy through the process. Schools using such an approach have reported an improved school climate [56].

Consequently, processes to improve the trust between students and school is key to facilitate reporting of cyberbullying that has been taking place in school or at home especially if the perpetrators are from the same school and also known to the victims. Borowsky and colleagues [57] studied the sense of connectedness and perceived caring by one's friends, parents and nonpaternal adults which serve as protective factors for groups of students involved in verbal and social bullying. Research has consistently shown that a whole-school approach by involving teachers, children and parents were more likely to have significant positive outcomes [58].

With a significant overlap of risk factors between school bullying and cyberbullying, anti-cyberbullying programs should be part of a broader anti-bullying program to improve disruptive behaviors, school climate and better self-efficacy $[59,60]$, thereby reducing downstream risk factors for subsequent selfharm and suicidal behaviors. These measures should be complemented by ongoing family therapy, parenting training and access to community mental health resources for youths who are involved in cyberbullying. Future research could study how existing ministry policies and practices mitigate the untoward ill effects of cyberbullying in schools and learning institutions.

\section{Conclusions}

With an increase in reporting of youth suicide reporting all over the world in relation to cyberbullying, more needs to be done to safeguard young people from the adverse effects of cyberbullying and to keep the cyberspace safe for all. Findings from research on cyberbullying should raise public awareness of the consequences of unhealthy cyber-usage and aid in the early detection of cyberbullying among school children and adolescents. In particular, the associations between cyberbullying and self-destructive behaviors suggest that cyberwellness programs should be considered as a component of larger suicide prevention efforts in schools and in the community. 


\section{Declarations}

\section{Acknowledgements}

We thank Qing Rong Chan, Rosie Lim, Jacky Tan, and Grace Yap for their assistance with data collection. We are grateful to the Ministry of Education Singapore, school principals, teachers, and counsellors for their support, and thank all students who participated in this research study.

\section{Authors' contribution}

SHO, JME, AS and DSSF conceived and designed the study. YRT and JZNK collected, analysed and interpreted the data. SHO and YRT drafted the manuscript. All authors read, critically reviewed and approved the final manuscript.

\section{Funding}

This work was funded by the National Healthcare Group Small Innovative Grant [Grant number SIG/14007]. The SIG was not involved in the study design, data collection and analysis, interpretation of data and manuscript preparation.

\section{Availability of data and materials}

The datasets used and/or analysed during the current study are available from the corresponding author on reasonable request.

\section{Ethics approval and consent to participate}

The study was approved by the Institute of Mental Health Clinical Research Committee (IMH CRC; 371/2012) and the National Healthcare Group Domain-Specific Review Board (DSRB; 2012/00801).

\section{Consent for publication}

Not applicable.

\section{Competing interests}

The authors declare that they have no competing interests.

\section{Author details}

${ }^{1}$ Department of Developmental Psychiatry, Institute of Mental Health, Singapore. 10 Buangkok View, Singapore 539747.

${ }^{2}$ Research Department, Singapore Children's Society. Radin Mas Community Club 
51 Telok Blangah Crescent, \#05-01, Singapore 098917.

${ }^{3}$ Department of Psychology, National University of Singapore. 9 Arts Link, Singapore 117570.

${ }^{4}$ Department of Child Psychiatry, University of Turku and Turku University Hospital, Turku, 20014 Turun yliopisto, Finland.

\section{Abbreviations}

MOE

Ministry of Education; SDQ:Strengths and Difficulties Questionnaire; SEL:Social and Emotional Learning

\section{References}

1. We Are Social: Digital in 2018: Global Overview. https://wearesocial.com/blog/2018/01/globaldigital-report-2018. 2018. Accessed January 3, 2019.

2. Hinduja S, Patchin JW. Bullying, cyberbullying, and suicide. Arch Suicide Res. 2010;14(3):206-21.

3. Juvonen J, Gross EF. Extending the school grounds? Bullying experiences in cyberspace. J Sch Health. 2008;78(9):496-505.

4. Raskauskas J, Stoltz AD. Involvement in traditional and electronic bullying among adolescents. Dev Psychol. 2007;43(3):564-75.

5. Diamanduros T, Downs E, Jenkins SJ. The role of school psychologists in the assessment, prevention, and intervention of cyberbullying. Psychol Sch. 2008;45(8):693-704.

6. Kowalski RM, Giumetti GW, Schroeder AN, Lattanner MR. Bullying in the digital age: a critical review and meta-analysis of cyberbullying research among youth. Psychol Bull. 2014;140(4):1073-137. 
7. Låftman SB, Modin B, Östberg V. Cyberbullying and subjective health: a large-scale study of students in Stockholm, Sweden. Child Youth Serv Rev. 2013;35(1):112-9.

8. Lee C, Shin N. Prevalence of cyberbullying and predictors of cyberbullying perpetration among Korean adolescents. Comput Human Behav. 2017;68:352-8.

9. Jung YE, Leventhal B, Kim YS, Park TW, Lee SH, Lee M, et al. Cyberbullying, problematic internet use, and psychopathologic symptoms among Korean youth. Yonsei Med J. 2014;55(3):826-30.

10. Görzig A. Adolescents' viewing of suicide-related web content and psychological problems: differentiating the roles of cyberbullying involvement. Cyberpsychol Behav Soc Netw. 2016;19(8):502-9.

11. Ang RP, Goh DH. Cyberbullying among adolescents: the role of affective and cognitive empathy, and gender. Child Psychiatry Hum Dev. 2010; 41(4):387-97.

12. Kwan GCE, Skoric MM. Facebook bullying: an extension of battles in school. Comput Human Behav. 2013;29(1):16-25.

13. Tokunaga RS. Following you home from school: a critical review and synthesis of research on cyberbullying victimisation. Comput Human Behav. 2010;26(3):277-87.

14. Ybarra ML, Boyd D, Korchmaros JD, Oppenheim JK. Defining and measuring cyberbullying within the larger context of bullying victimisation. J Adolesc Health. 2012;51(1):53-8.

15. Beckman L, Hagquist C, Hellström L. Does the association with psychosomatic health problems differ between cyberbullying and traditional bullying? Emot Behav Diffic. 2012;17(3-4):421-34.

16. Wolke D, Lee K, Guy A. Cyberbullying: a storm in a teacup? Eur Child Adolesc Psychiatry. 2017;26(8):899-908. 
17. Kubiszewski V, Fontaine R, Potard C, Auzoult L. Does cyberbullying overlap with school bullying when taking modality of involvement into account? Comput Human Behav. 2015;43:49-57.

18. Campbell M, Spears B, Slee P, Butler D, Kift S. Victims' perceptions of traditional and cyberbullying, and the psychosocial correlates of their victimisation. Emot Behav Diffic. 2012;17(3-4):389-401.

19. Smith PK, Mahdavi J, Carvalho M, Fisher S, Russell S, Tippett N. Cyberbullying: its nature and impact in secondary school pupils. J Child Psychol Psychiatry. 2008;49(4):376-85.

20. Perren S, Dooley J, Shaw T, Cross D. Bullying in school and cyberspace: associations with depressive symptoms in Swiss and Australian adolescents. Child Adolesc Psychiatry Ment Health. 2010;4:28.

21. Aboujaoude E, Savage MW, Starcevic V, Salame WO. Cyberbullying: review of an old problem gone viral. J Adolesc Health. 2015;57(1):10-8.

22. Bauman S. Cyberbullying: what does research tell us? Theory Pract. 2013;52(4):249-56.

23. Kowalski RM, Limber SP. Psychological, physical, and academic correlates of cyberbullying and traditional bullying. J Adolesc Health. 2013;53(1 Suppl):S13-20.

24. Hay C, Meldrum R. Bullying victimization and adolescent self-harm: testing hypotheses from general strain theory. J Youth Adolesc. 2010;39(5):446-59.

25. Cable News Network (CNN). 'Alarming' rise in children hospitalized with suicidal thoughts or actions. http://edition.cnn.com/2017/05/05/health/children-teens-suicide-study/index.html. 2017. Accessed January 32019. 
26. Patton GC, Coffey C, Sawyer SM, Viner RM, Haller DM, Bose K, et al. Global patterns of mortality in young people: a systematic analysis of population health data. Lancet. 2009;374(9693):881-92.

27. Centers for Disease Control and Prevention (CDC). Nonfatal injury data. https://www.cdc.gov/injury/wisqars/nonfatal.html. 2018. Accessed January 32019.

28. Nock MK, Borges G, Bromet EJ, Cha CB, Kessler RC, Lee S. Suicide and suicidal behavior. Epidemiol Rev. 2008;30(1):133-54.

29. Joiner TE. Why people die by suicide. Cambridge, MA: Harvard University Press; 2005.

30. Klomek AB, Marrocco F, Kleinman M, Schonfeld IS, Gould MS. Peer victimization, depression, and suicidality in adolescents. Suicide Life Threat Behav. 2008;38(2):166-80.

31. Jo MJ, Lee JW, Sung M, Song SH, Lee YM, Lee JJ, et al. Psychopathology associated with cyberbullying among middle school students. J Korean Neuropsychiatr Assoc. 2015;54(2):245-51.

32. WHO. Global Health Observatory data repository - Suicide rate estimates, crude, 15-29 and 30-49 years. Estimates by country [online]. http://apps.who.int/gho/data/node.main.MHSUICIDEAGEGROUPS15293049?lang=en. Assessed March 132019.

33. Sourander A, Brunstein Klomek A, Ikonen M, Lindroos J, Luntamo T, Koskelainen M, et al. Psychosocial risk factors associated with cyberbullying among adolescents: a population-based study. Arch Gen Psychiatry. 2010;67(7):720-8.

34. Singapore Department of Statistics. Population trends 2018, Singapore. https://www.singstat.gov.sg/-/media/files/publications/population/population2018.pdf. 2018. 
Accessed October 282019.

35. Hinduja S, Patchin JW. Bullying beyond the schoolyard: Preventing and responding to cyberbullying. Thousand Oaks, CA: Corwin Press; 2009.

36. Goodman R. The Strengths and Difficulties Questionnaire: a research note. J Child Psychol Psychiatry. 1997;38(5):581-6.

37. Goodman A, Lamping DL, Ploubidis GB. When to use broader internalising and externalising subscales instead of the hypothesised five subscales on the Strengths and Difficulties Questionnaire (SDQ): data from British parents, teachers and children. J Abnorm Child Psychol. 2010;38(8):117991.

38. Gámez-Guadix M, Orue I, Smith PK, Calvete E. Longitudinal and reciprocal relations of cyberbullying with depression, substance use, and problematic internet use among adolescents. J Adolesc Health. 2013;53(4):446-52.

39. Bonanno RA, Hymel S. Cyber bullying and internalising difficulties: above and beyond the impact of traditional forms of bullying. J Youth Adolesc. 2013;42(5):685-97.

40. Kowalski RM, Limber SP, Agatston PW. Cyberbullying: bullying in the digital age. 2nd ed. Malden, MA: Wiley-Blackwell; 2012.

41. Juvonen J, Graham S, Schuster MA. Bullying among young adolescents: the strong, the weak, and the troubled. Pediatrics. 2003;112(6 Pt 1):1231-7.

42. Foody M, Samara M, Carlbring P. A review of cyberbullying and suggestions for online psychological therapy. Internet Interv. 2015;2(3):235-42.

43. Wang J, Nansel TR, lannotti RJ. Cyber and traditional bullying: differential association with depression. J Adolesc Health. 2011;48(4):415-7. 
44. Van der Wal MF, de Wit CAM, Hirasing RA. Psychosocial health among young victims and offenders of direct and indirect bullying. Pediatrics. 2003;111(6):1312-7.

45. Nixon CL. Current perspectives: the impact of cyberbullying on adolescent health. Adolesc Health Med Ther. 2014;5:143-58.

46. Price M, Dalgleish J. Cyberbullying: experiences, impacts and coping strategies as described by Australian young people. Youth Studies Austr. 2010;29(2):51-9.

47. Beran T, Li Q. Cyber-Harassment: A Study of a New Method for an Old Behavior. J Educ Comput Res. 2005;32(3):265-77.

48. Ortega R, Elipe P, Mora-Merchan JA, Genta ML, Brighi A, Guarini A, et al. The emotional impact of bullying and cyberbullying on victims: a European cross-national study. Aggress Behav. 2012;38(5):342-56.

49. Macháčková H, Dedkova L, Sevcikova A, Cerna A. Bystanders' Support of Cyberbullied Schoolmates. J Community Appl Soc Psychol. 2013;23(1):25-36.

50. Williams KR, Guerra NG. Prevalence and predictors of internet bullying. J Adolesc Health. 2007;41(6 Suppl 1):S14-21.

51. Khong JZN, Tan YR, Elliott JM, Fung DSS, Sourander A, Ong SH. Traditional Victims and Cybervictims: Prevalence, Overlap, and Association with Mental Health Among Adolescents in Singapore. School Mental Health. Advance online publication. 2019. doi: 10.1007/s12310-01909337-x. 
52. Ministry of Education. Social and Emotional Learning. https://www.moe.gov.sg/education/programmes/social-and-emotional-learning. 2016. Accessed January 32019.

53. Diekstra R. Effectiveness of school-based social and emotional education programmes worldwide. In: Botin FM, editor. Social and Emotional Education: An International Analysis. Santender, Spain: Fundacion Marcelino Botin 2008;255-312.

54. Ministry of Justice. Restorative Justice Facilitator Induction Training: Trainee Module. http://www,justice.govt.nz/policy/criminal-justice/restorative-justice/restorative-justice-informationfor-providers/doceumnts/copy_of_MODULE-1-for_internet_1.pdf. 2009. Assessed April 82019.

55. McCold P. Restorative justice and the role of the community. In Galaway, B. \& Hudson., J. (Eds.), Restorative Justice: International Perspectives (pp.85-102). Monsey, New York: Criminal Justice Press; 1996.

56. Grossi PK, dos Stantos, AM. Bullying in Brazilian schools and restorative practices. Canadian Journal of Education. 2012;35(1), 120-136.

57. Borowsky IW, Taliaferro LA, McMorris BJ. Suicidal thinking and behavior among youth involved in verbal and social bullying: risk and protective factors. J Adolesc Health. 2013;53(1 Suppl):S4-12.

58. Vreeman RC, Carroll AE. A systematic review of school-based interventions to prevent bullying. Arch Pediatr Adolesc Med. 2007;161(1):78-88.

59. Baldry AC, Farrington DP, Sorrentino A. "Am I at risk of cyberbullying"? A narrative review and conceptual framework for research on risk of cyberbullying and cybervictimization: The risk and 
needs assessment approach. Aggress Violent Behav. 2015;23:36-51.

60. Capurso S, Paradžik L, Mratović MČ. Cyberbullying among children and adolescents - an overview of epidemiological studies and effective prevention programs. Crim Soc Integr J. 2017;25(1):127-37.

\section{Tables}

Table 1

Demographic Characteristics across Cyberbullying Status.

\begin{tabular}{lccccc}
\hline Variable & $\begin{array}{c}\text { All Groups } \\
(n=3,305)\end{array}$ & $\begin{array}{c}\text { Non-involved } \\
(n=2,845)\end{array}$ & $\begin{array}{c}\text { Cybervictims } \\
(n=240)\end{array}$ & $\begin{array}{c}\text { Cyberbullies } \\
(n=60)\end{array}$ & $\begin{array}{c}\text { Cyberbully-victims } \\
(n=160)\end{array}$ \\
\hline Gender $^{1}[n(\%)]$ & & & \\
Female & $1,648(49.9)$ & $1,405(49.4)$ & $157(65.4)^{*}$ & $22(36.7)^{\wedge}$ & $64(40.0)^{\wedge}$ \\
\hline Male & $1,657(50.1)$ & $1,440(50.6)$ & $83(34.6)^{\wedge}$ & $38(63.3)^{*}$ & $96(60.0)^{*}$ \\
\hline Ethnicity ${ }^{2}[n(\%)]$ & & & & \\
\hline Chinese & $2,194(66.4)$ & $1,894(66.6)$ & $154(64.2)$ & $37(61.7)$ & $109(68.1)$ \\
\hline Malay & $734(22.2)$ & $630(22.1)$ & $55(22.9)$ & $14(23.3)$ & $35(21.9)$ \\
\hline Indian & $197(6.0)$ & $172(6.0)$ & $13(5.4)$ & $4(6.7)$ & $8(5.0)$ \\
\hline Others & $180(5.4)$ & $149(5.2)$ & $18(7.5)$ & $5(8.3)$ & $8(5.0)$ \\
\hline Age & & & 14.23 & 14.46 \\
\hline Mean (years) & 14.42 & 14.44 & 14.30 & \\
\hline
\end{tabular}

Note: Values have an adjusted residual ${ }^{*}$ greater than $2.0 ;{ }^{\wedge}$ smaller than -2.0

${ }^{1} \chi 2(3, n=3,305)=33.89, p<.001$, Cramer's $V=.10$

${ }^{2} \chi^{2}(9, n=3,305)=4.08, p=.91$, Cramer's $V=.02$

${ }^{3} F(3,3,293)=1.67, p=.17, \eta^{2}=.002$

Table 3

Associations between Cyberbullying Status Groups and Self-harming and Suicidal-related Behaviors. 


\begin{tabular}{|c|c|c|c|c|c|c|c|c|c|c|}
\hline \multirow[t]{2}{*}{ Characteristics } & \multirow[t]{2}{*}{ Total, No } & \multicolumn{3}{|c|}{ Cybervictims } & \multicolumn{3}{|c|}{ Cyberbullies } & \multicolumn{3}{|c|}{ Cyberbully-victims } \\
\hline & & Wald & $\begin{array}{c}\text { OR } \\
(95 \% \mathrm{CI})\end{array}$ & $p$ & Wald & $\begin{array}{c}\text { OR } \\
(95 \% \mathrm{CI})\end{array}$ & $p$ & Wald & $\begin{array}{c}\text { OR } \\
(95 \% \mathrm{CI})\end{array}$ & $p$ \\
\hline Self-harm behaviors & 3290 & 73.69 & $\begin{array}{c}3.6 \\
(2.7-4.9)\end{array}$ & $<.001$ & 7.62 & $\begin{array}{c}2.4 \\
(1.3-4.5)\end{array}$ & .006 & 32.41 & $\begin{array}{c}3.0 \\
(2.1-4.4)\end{array}$ & $<.001$ \\
\hline Suicidal ideation & 3297 & 105.15 & $\begin{array}{c}4.3 \\
(3.2-5.7)\end{array}$ & $<.001$ & 8.35 & $\begin{array}{c}2.3 \\
(1.3-4.1)\end{array}$ & .004 & 27.64 & $\begin{array}{c}2.6 \\
(1.8-3.7)\end{array}$ & $<.001$ \\
\hline Suicide attempts & 3296 & 64.90 & $\begin{array}{c}4.7 \\
(3.2-6.9)\end{array}$ & $<.001$ & 11.76 & $\begin{array}{c}3.9 \\
(1.8-8.6)\end{array}$ & $<.001$ & 45.08 & $\begin{array}{c}5.0 \\
(3.1-8.0\end{array}$ & $<.001$ \\
\hline
\end{tabular}

Abbreviation: OR, odds ratio; CI, confidence interval

Note. Results of logistic regression analyses. All analyses were adjusted with the effect of gender, ethnicity and age. Reference group: noninvolved.

Table 4

Help-seeking Behaviors among Cybervictimised Participants.

\begin{tabular}{|c|c|c|c|c|c|c|}
\hline Help-seeking behaviors & $\begin{array}{c}\text { Total } \\
(n=399)\end{array}$ & $\begin{array}{c}\text { Male } \\
(n=178)\end{array}$ & $\begin{array}{l}\text { Female } \\
(n=221)\end{array}$ & $x^{2}$ & $p$ & Cramer's V \\
\hline \multicolumn{7}{|l|}{ Help-seeking $[n(\%)]$} \\
\hline Yes & $208(52.1)$ & $74(41.6)$ & $134(64.4)$ & 13.60 & $<.001$ & .19 \\
\hline No & $191(47.9)$ & $104(58.4)$ & $87(39.4)$ & & & \\
\hline \multicolumn{7}{|l|}{ Sources $[n(\%)]$} \\
\hline Friends & $170(81.7)$ & $58(78.4)$ & 112 (83.6) & 0.55 & .46 & .06 \\
\hline Parents & $85(40.9)$ & $31(41.9)$ & $54(40.3)$ & 0.01 & .94 & .02 \\
\hline Siblings & $66(31.7)$ & $24(32.4)$ & $42(31.3)$ & 0 & .99 & .01 \\
\hline Teachers & $53(25.5)$ & $24(32.4)$ & 29 (21.6) & 2.38 & .12 & .12 \\
\hline $\begin{array}{l}\text { Other adults at } \\
\text { school }\end{array}$ & $32(15.4)$ & $10(13.5)$ & $22(16.4)$ & 0.13 & .72 & .04 \\
\hline $\begin{array}{c}\text { Mental health } \\
\text { professionals }\end{array}$ & $16(7.7)$ & $5(6.8)$ & $11(8.2)$ & 0.01 & .92 & .03 \\
\hline Others & $11(5.3)$ & $2(2.7)$ & $9(6.7)$ & 0.84 & .36 & .09 \\
\hline
\end{tabular}

\section{Table 2}

Due to technical limitations, table 2 is only available as a download in the supplemental files section

\section{Supplementary Files}

This is a list of supplementary files associated with this preprint. Click to download. 
- Table23Novv2.docx

- STROBEchecklistcrosssectional4.doc 